\title{
Exigências de lisina, com base no conceito de proteína ideal, para suínos machos castrados dos 96 aos $120 \mathrm{~kg}$, selecionados para eficiência de crescimento
}

\author{
[Lysine requirements, based on ideal protein concept, for barrows with high genetic potential \\ for growth efficiency, from 96 to $120 \mathrm{~kg}]$ \\ C.L.C. Arouca $^{1}$, D.O. Fontes ${ }^{2}$, , J.A.F. Veloso ${ }^{2}$, H.F.V. Moreira ${ }^{3}$, P.C. Marinho ${ }^{1}$ \\ ${ }^{1}$ Estudante de Pós-Graduação - Escola de Veterinária da UFMG \\ ${ }^{2}$ Departamento de Zootecnia - Escola de Veterinária da UFMG \\ Caixa Postal 567 \\ 30123-970 - Belo Horizonte, MG \\ ${ }^{3}$ Mestre em Zootecnia
}

\section{RESUMO}

Determinaram-se as exigências de lisina para suínos machos castrados utilizando-se 50 animais em delineamento experimental de blocos ao acaso, com cinco tratamentos $(0,5 ; 0,6 ; 0,7 ; 0,8$ e $0,9 \%$ de lisina total), cinco repetições e dois animais por baia. Adicionaram-se aminoácidos sintéticos para manter o nível de acordo com o perfil da proteína ideal. Houve efeito quadrático dos tratamentos sobre o ganho de peso diário e conversão alimentar. O modelo linear response plateau ajustou-se melhor aos dados de conversão alimentar. Observou-se aumento linear do consumo de lisina diário, espessura de toucinho na $10^{\mathrm{a}}$ costela e espessura de toucinho na última costela. Não houve efeito sobre o consumo de ração diário, espessura de toucinho no $\mathrm{P}_{1}$, espessura de toucinho no $\mathrm{P}_{2}$, profundidade de lombo, porcentagem de carne magra, taxa de deposição de carne magra diária, rendimento de carcaça, comprimento de carcaça pelo método brasileiro, comprimento de carcaça pelo método americano e sobre o peso e rendimento dos cortes cárneos. Suínos machos castrados de 96 a $120 \mathrm{~kg}$, selecionados para eficiência de crescimento, exigiram $0,61 \%$ de lisina total, correspondendo ao consumo de $22,74 \mathrm{~g} / \mathrm{dia}$.

Palavras-chave: suíno, lisina, terminação tardia, desempenho, carcaça

\begin{abstract}
Lysine requirements of hybrid barrows (AG 1050 grandmother's brothers), using 50 animals in a completely randomized block design with five dietary treatments $(.50 ; .60 ; .70 ; .80$ and $.90 \%$ of total lysine), five replicates and two animals per experimental unit were estimated. Crystalline amino acids were added to keep amino acids levels according to the ideal protein profile. Quadratic effects of treatments on average daily gain and on feed conversion were observed. Linear effects of treatments on daily lysine intake, on $10^{\text {th }}$ rib fat depth and on last rib fat depth were observed. No effects of lysine level on daily feed intake, $P_{1}$ back fat thickness, $P_{2}$ back fat thickness, loin depth, lean percentage, daily lean gain, carcass yield, carcass length, carcass length measured by Brazilian method, weights and sub primal cut yields were found. Barrows selected for high growth efficiency, from 96 to $120 \mathrm{~kg}$, required .61\% of total lysine, which corresponds to approximately $22.74 \mathrm{~g} /$ day of lysine intake.
\end{abstract}

Keywords: swine, lysine, late finishing, performance, carcass

Trabalho financiado pelo CNPq

Recebido para publicação em 20 de janeiro de 2004

Recebido para publicação, após modificações, em 30 de julho de 2004

*Autor para correspondência (corresponding author)

E-mail: dalton@vet.ufmg.br 


\section{INTRODUÇÃO}

Sabe-se que há grandes diferenças na habilidade de ganhar peso e na eficiência de conversão dos nutrientes, e que linhagens modernas têm apresentado elevado ritmo de crescimento, com alta taxa de deposição de carne magra (Close, 1994).

A lisina tem sido considerada o primeiro aminoácido limitante na dieta para suínos à base de milho e farelo de soja por ser exigida em maior quantidade para deposição de carne e em razão do destino metabólico para a deposição de tecido magro (Kessler, 1998). Entretanto, as estimativas das exigências desse aminoácido para suínos têm apresentado grande variação nas diferentes fases de crescimento, pois, segundo o Nutrient... (1998), as exigências podem variar conforme o genótipo, sexo e densidade populacional.

As estratégias de alimentação devem ser estabelecidas de forma específica para cada grupo genético, pois quanto maior o potencial genético para deposição de carne maior será a exigência diária de lisina na ração (Friesen et al., 1994a). O ajuste da lisina e da proteína da dieta às exigências dos animais pode, portanto, resultar em melhor eficiência alimentar e, conseqüentemente, melhor custo/benefício de produção.

O objetivo do trabalho foi avaliar o efeito de diferentes níveis de lisina da dieta sobre o desempenho e características de carcaça de suínos dos 96 aos $120 \mathrm{~kg}$ e estabelecer as exigências de lisina de animais machos castrados, selecionados geneticamente para alta eficiência de crescimento.

\section{MATERIAL E MÉTODOS}

O experimento foi realizado entre os meses de julho a outubro de 2002. Foram utilizados 50 suínos machos castrados, resultantes do cruzamento de duas linhas genéticas oriundas das raças Landrace e Large White, selecionados geneticamente para características reprodutivas e eficiência de crescimento (irmãos da avó AG 1050), com peso inicial médio de $96,19 \pm 1,49 \mathrm{~kg}$, distribuídos em um delineamento experimental de blocos ao acaso, com cinco tratamentos $(0,5$;
0,$6 ; 0,7 ; 0,8$ e $0,9 \%$ de lisina na ração), cinco repetições e dois animais por unidade experimental. O critério para distribuição dos animais dentro de cada bloco foi o peso inicial. As dietas, produzidas de acordo com Arouca et al. (2004) e fornecidas à vontade, foram pesadas duas vezes por semana, enquanto que os animais o foram, individualmente, no início e ao final do período, quando foi determinado o ganho de peso diário (GPD), a conversão alimentar (CA), o consumo de ração diário (CRD) e o consumo de lisina diário (CLD). A composição das dietas é a mesma apresentada por Arouca et al. (2004) em outro experimento.

No primeiro e último dia do período experimental foram tomadas medidas ultrasônicas, in vivo, para algumas características de carcaça (espessura de toucinho, profundidade de lombo e porcentagem de carne magra), utilizando-se equipamento portátil de ultra-som $\left(\right.$ PigLog- $\left.105^{\circledR}\right)$, de acordo com Arouca et al. (2004). Ao término do experimento, quando atingiram, em média, $120,60 \pm 3,31 \mathrm{~kg}$, os animais foram encaminhados ao frigorífico, onde foram abatidos após jejum de 10 horas.

Para a avaliação das características de carcaça, mediram-se, de acordo com Arouca et al. (2004), as variáveis: rendimento de carcaça (RC), comprimento de carcaça pelo método americano (CCMA) e espessura de toucinho na $10^{\mathrm{a}}$ costela $\left(\mathrm{ET} 10^{\mathrm{a}}\right)$. Para o comprimento de carcaça pelo método brasileiro (CCMB) e espessura de toucinho na última costela (ETUL), as medições foram feitas de acordo com Associação... (1973). As carcaças foram desossadas de acordo com o procedimento padrão do frigorífico, obtendo-se: peso do pernil (PPO), peso do pernil desossado (PPSO), peso do carré (PCAR), peso da paleta (PPAL), peso da barriga (PBAR), rendimento de pernil (RP) e rendimento de carré (RCAR).

Os resultados de desempenho, das medidas ultrasônicas in vivo e das características de carcaça foram submetidos à análise de variância utilizando-se o pacote estatístico computacional SAEG (Sistema..., 2000). Para análise das medidas ultra-sônicas in vivo ao final do experimento utilizou-se como covariável o resultado correspondente à mesma variável no início do experimento. Estimou-se a exigência de lisina utilizando os modelos de regressão linear, quadrático e/ou o modelo descontínuo linear 
response plateau (LRP), de acordo com o melhor ajuste obtido para cada variável.

\section{RESULTADOS E DISCUSSÃO}

As temperaturas médias mínima e máxima verificadas no período experimental foram $12,98 \pm 2,37^{\circ} \mathrm{C}$ e $27,75 \pm 3,26^{\circ} \mathrm{C}$, respectivamente.

Os resultados para ganho diário de peso, consumo diário de ração, conversão alimentar e consumo diário de lisina encontram-se na Tab. 1.
Observou-se efeito quadrático $(\mathrm{P}<0,04)$ sobre o GPD dos animais em razão do aumento do nível de lisina da ração (Fig. 1). Os animais responderam com aumento do GPD até o nível de $0,75 \%$ de lisina $(0,235 \% /$ Mcal de EM), correspondendo ao consumo de lisina total de $27,84 \mathrm{~g} /$ dia. Friesen et al. (1995) relataram efeito quadrático dos níveis de lisina digestível da dieta $(0,44$ a $0,94 \%)$ sobre o GPD de leitoas, de 72 a $136 \mathrm{~kg}$.

Tabela 1. Ganho de peso diário, consumo de ração diário, conversão alimentar e consumo de lisina diário de acordo com o nível de lisina da dieta de suínos dos 96 aos $120 \mathrm{~kg}$ de peso

\begin{tabular}{|c|c|c|c|c|c|c|}
\hline \multirow{2}{*}{ Característica } & \multicolumn{5}{|c|}{ Nível de lisina da ração (\%) } & \multirow{2}{*}{$\begin{array}{l}\text { CV } \\
(\%)\end{array}$} \\
\hline & 0,5 & 0,6 & 0,7 & 0,8 & 0,9 & \\
\hline Ganho de peso diário $(\mathrm{g})^{1}$ & 967 & 1115 & 1160 & 1202 & 1107 & 11,38 \\
\hline Consumo de ração diário $(\mathrm{g})$ & 3638 & 3664 & 3739 & 3944 & 3516 & 7,58 \\
\hline Conversão alimentar $(\mathrm{g} / \mathrm{g})^{2}$ & 3,78 & 3,30 & 3,25 & 3,29 & 3,18 & 7,13 \\
\hline Consumo de lisina (g/dia) ${ }^{3}$ & 18,19 & 21,99 & 26,17 & 31,55 & 31,64 & 7,17 \\
\hline
\end{tabular}

${ }^{1}$ Efeito quadrático $(\mathrm{P}<0,04)$

${ }^{2}$ Efeito quadrático $(\mathrm{P}<0,06)$ e linear response plateau $(\mathrm{LRP})$.

${ }^{3}$ Efeito linear $(\mathrm{P}<0,01)$.

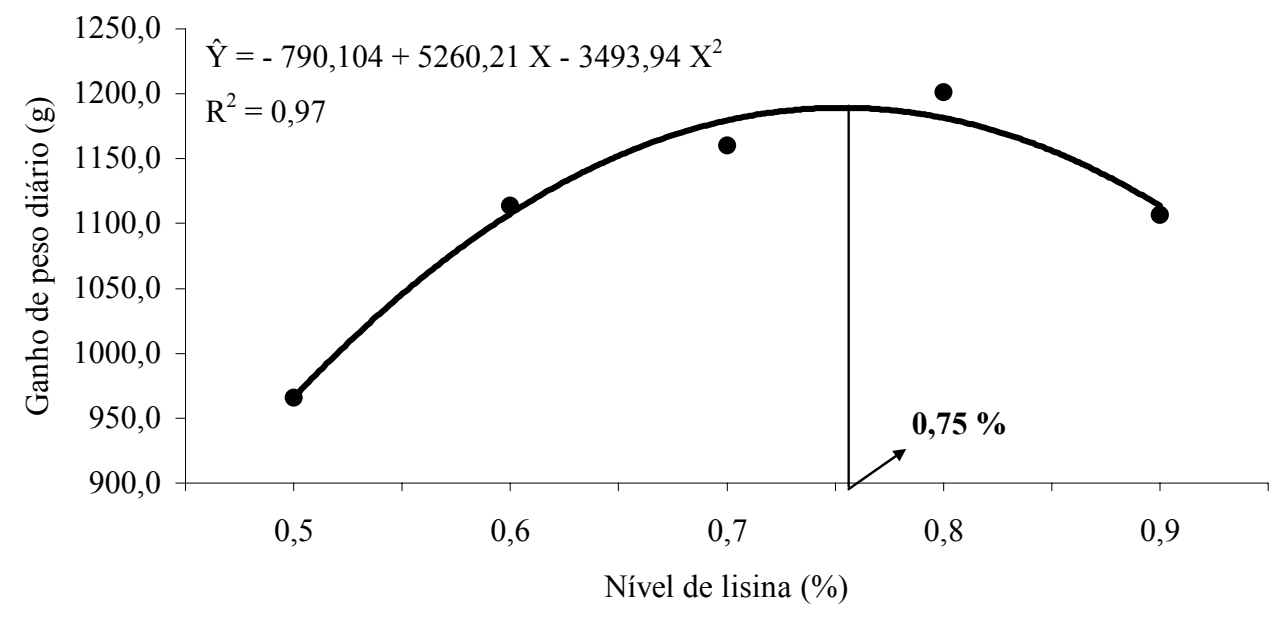

Figura 1. Ganho diário de peso de acordo com o nível de lisina da dieta de suínos dos 96 aos 120kg de peso.

Bertol et al. (2000) verificaram decréscimo linear no GPD de machos castrados alimentados com diferentes níveis de lisina digestível $(0,6$ a
$0,90 \%$ ), entre 80 e $120 \mathrm{~kg}$. GPD médio $(1110 \mathrm{~g} / \mathrm{dia})$ obtido está próximo aos valores médios obtidos por Hahn et al. (1995) e Oliveira 
et al. (2001), que correspondem a 1065 e $1063 \mathrm{~g} /$ dia, respectivamente, e acima do observado por Friesen et al. (1994b), 915g/dia. Essas variações obtidas de diferentes trabalhos podem estar associadas às diferenças entre os grupos genéticos estudados e sistemas de alimentação (Stahly et al., 1991), ou ao perfil de aminoácidos e energia das dietas, sexo e estado de saúde dos animais.

Não foi verificado efeito $(\mathrm{P}>0,10)$ do nível de lisina sobre o CRD. Vários autores (Loughmiller et al., 1998; Cline et al., 2000) também não observaram diferença no CRD em função do nível de lisina da ração. Bertol et al. (2000), Oliveira et al. (2001) e Oliveira et al. (2002a) observaram diminuição linear no CRD com o aumento do nível de lisina. Diversos fatores como temperatura ambiente, grupo genético, saúde e densidade populacional podem influenciar o CRD dos suínos, nas várias fases do crescimento. Animais selecionados geneticamente para velocidade de crescimento ou eficiência reprodutiva normalmente apresentam padrão de consumo superior àqueles selecionados para elevadas taxas de deposição de carne magra na carcaça, o que pode explicar o elevado CRD médio $(3700 \mathrm{~g} / \mathrm{dia})$ verificada neste experimento.

Foi observado efeito quadrático $(\mathrm{P}<0,06)$ dos tratamentos sobre a CA, que melhorou até o nível de $0,80 \%$ de lisina total. Contudo, o modelo descontínuo LRP foi o que melhor se ajustou aos resultados obtidos $\left(\mathrm{R}^{2}=1,00\right)$, estimando em $0,61 \%(0,190 \% / \mathrm{Mcal}$ de EM) o nível de lisina total a partir do qual os valores permanecem no máximo, o que representou consumo de lisina total estimado de $22,74 \mathrm{~g} / \mathrm{dia}$ (Fig. 2). A relação lisina:proteína total correspondeu a 4,5\% no nível de lisina, que proporcionou o melhor resultado de CA, valor semelhante aos observados por Friesen et al. (1994b) e Loughmiller et al. (1998), e preconizado pelo Nutrient... (1998).

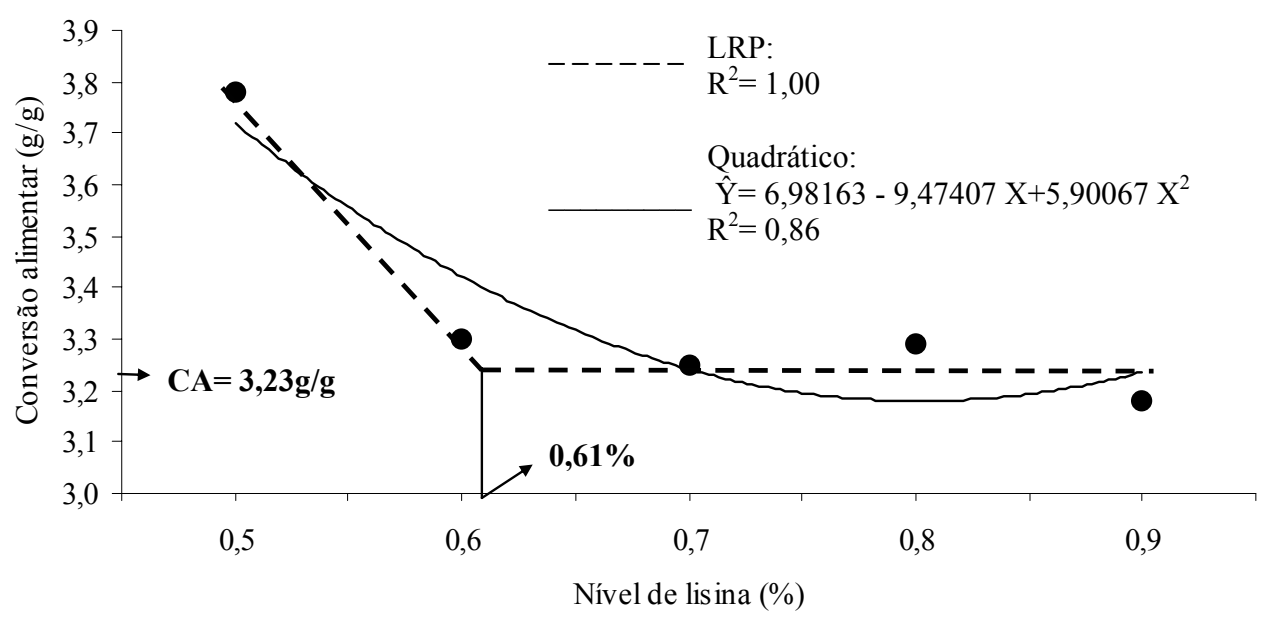

Figura 2. Conversão alimentar de acordo com o nível de lisina da dieta de suínos dos 96 aos $120 \mathrm{~kg}$ de peso.

O nível de lisina obtido $(0,61 \%)$, que propiciou o melhor resultado de CA, é coerente com o preconizado pelo Nutrient... (1998), para suínos machos castrados, de 80 a $120 \mathrm{~kg}$, de $0,60 \%$ de lisina total. Este valor é superior ao relatado por Friesen et al. (1994b) para suínos machos castrados de alto e médio potencial para deposição de carne magra, de $0,55 \%$ de lisina. Oliveira et al. (2001) e Oliveira et al. (2002a), ao utilizarem animais selecionados geneticamente para alta deposição de carne magra na carcaça, obtiveram resultados superiores, respectivamente de $0,76 \%$ e $0,80 \%$ de lisina total. O valor de CA $(3,23 \mathrm{~g} / \mathrm{g})$, obtido no nível de lisina a partir do 
qual os dados permaneceram no máximo, foi inferior ao obtido por Hahn et al. (1995) $(3,53 \mathrm{~g} / \mathrm{g})$, também estimado pelo modelo LRP, ao trabalharem com machos castrados (PIC Linha 26 X Camborough 15).

Constatou-se aumento linear $(\mathrm{P}<0,01)$ do $\mathrm{CLD}$, em razão do aumento do nível de lisina da dieta, uma vez que não foi observado aumento do CRD entre os tratamentos, de acordo com a equação $\hat{\mathrm{Y}}=0,382864+36,4660 \mathrm{X} \quad\left(\mathrm{R}^{2}=0,95\right)$. Resultados semelhantes foram relatados por Cline et al. (2000), Oliveira et al. (2001) e Oliveira et al. (2002a).

Os resultados de espessura de toucinho no ponto $\mathrm{P}_{1}\left(\mathrm{ETP}_{1}\right)$, espessura de toucinho no ponto $\mathrm{P}_{2}$
$\left(\mathrm{ETP}_{2}\right)$, profundidade de lombo (PL), porcentagem de carne magra (PCM) e taxa de deposição de carne magra diária (TDCMD) encontram-se na Tab. 2. Não foi observado efeito $(\mathrm{P}>0,10)$ do nível de lisina sobre a $\mathrm{ETP}_{1}$ e $\mathrm{ETP}_{2}$, medidas por ultra-som. Moreira et al. (2002), ao trabalharem com níveis de lisina para suínos machos castrados na fase de terminação, verificaram que as medidas de ET, obtidas no animal vivo, não foram influenciadas pelo nível de lisina nos grupos genéticos estudados. Gasparotto et al. (2001), ao avaliarem os efeitos de níveis de lisina $(0,75$ a $1,20 \%)$ para suínos machos castrados de dois grupos genéticos, na fase de crescimento, verificaram que houve diminuição da ETP1.

Tabela 2. Espessura de toucinho em $\mathrm{P}_{1}$ e em $\mathrm{P}_{2}$, profundidade de lombo, porcentagem de carne magra e taxa de deposição de carne magra diária (TDCMD) de acordo com o nível de lisina da dieta de suínos dos 96 aos $120 \mathrm{~kg}$ de peso

\begin{tabular}{lcccccc}
\hline \multirow{2}{*}{ Característica } & \multicolumn{3}{c}{ Nível de lisina da ração (\%) } & \multicolumn{3}{c}{ CV } \\
\cline { 2 - 7 } & 0,5 & 0,6 & 0,7 & 0,8 & 0,9 & $(\%)$ \\
\hline $\mathrm{ETP}_{1}(\mathrm{~mm})^{*}$ & 15,49 & 15,26 & 15,94 & 16,90 & 16,56 & 14,91 \\
$\mathrm{ETP}_{2}(\mathrm{~mm})^{*}$ & 17,71 & 19,06 & 18,85 & 18,85 & 18,57 & 12,86 \\
Profundidade de lombo (mm) & 49,25 & 49,89 & 50,86 & 53,43 & 48,89 & 5,37 \\
Carne magra (\%)* & 54,72 & 54,14 & 54,02 & 53,30 & 53,74 & 4,38 \\
TDCMD (g/dia) & 400 & 474 & 446 & 422 & 435 & 23,48 \\
\hline
\end{tabular}

* Valores ajustados pelas mesmas variáveis medidas no início do experimento.

Não houve efeito $(\mathrm{P}>0,10)$ dos tratamentos sobre a PL, semelhante ao ocorrido no trabalho de Moreira et al. (2002).

A PCM não foi influenciada pelo nível de lisina da dieta $(\mathrm{P}>0,10)$. Bertol et al. (2000), ao estudarem machos castrados e fêmeas, de 80 a $120 \mathrm{~kg}$, verificaram diminuição não linear na PCM para os machos e diminuição linear para as fêmeas. Loughmiller et al. (1998) e Cline et al. (2000) verificaram que a PCM aumentou de modo linear, de acordo com o nível de lisina. $\mathrm{O}$ valor médio de PCM $(54,0 \%)$ foi semelhante ao relatado por Souza Filho et al. (2000). Bertol et al. (2000), Kill et al. (2002a) e Kill et al. (2002b) observaram valores superiores ao obtido neste estudo, respectivamente, 58,3; 57,9 e $59,2 \%$, obtidos por dissecação.

Não se observou efeito $(\mathrm{P}>0,10)$ dos tratamentos sobre a TDCMD. Entretanto, pode-se verificar que o nível de lisina $(0,61 \%)$ a partir do qual os valores de CA permaneceram no máximo coincidiu com o maior valor de TDCMD (474g/dia), 10,2\% superior aos demais. Resultado semelhante foi obtido por Gonçalves et al. (1999), que ao avaliarem características de carcaça de suínos híbridos, de 30 a $112 \mathrm{~kg}$, não observaram efeito do nível de lisina sobre a taxa de crescimento do músculo. $\mathrm{O}$ valor médio para TDCMD (435g/dia) foi superior ao obtido por Hahn et al. (1995), Gonçalves et al. (1999) e Cline et al. (2000), respectivamente, 323, 306 e $415 \mathrm{~g} / \mathrm{dia}$.

Segundo Friesen et al. (1994b) e Friesen et al. (1995), a deposição de tecido muscular está relacionada com a quantidade de proteína ou lisina ingerida pelo animal. Entretanto, os resultados de Friesen et al. (1994b) indicaram que a magnitude da resposta a maiores níveis de lisina dietética pode estar diminuída com o aumento do peso do suíno acima de $100 \mathrm{~kg}$, o que poderia ter acontecido no presente estudo. Nos 
animais mais pesados pode ocorrer maior deposição de lipídeos em detrimento da deposição de proteína na carcaça, sendo função do potencial de deposição de carne magra do animal. Schinckel (1992), citado por Friesen et al. (1995), observou que a taxa máxima de ganho protéico é atingida entre 40 e $50 \mathrm{~kg}$ de peso, dependendo do genótipo, ambiente, estado de saúde e nutrição. Entretanto, a deposição de lipídeos continua a aumentar até pesos mais elevados. Assim, nos suínos em crescimento, ocorre alteração na relação deposição de gordura e proteína, isto é, há aumento de proteína na carcaça como resultado do aumento da ingestão da lisina da dieta. Entretanto, quando ocorre aumento de ganho lipídico com taxa de ganho protéico semelhante, pode estar havendo excesso de ingestão de energia (Friesen et al. 1995). Além disso, o aumento na gordura da carcaça é potencialmente associado à ingestão de alimentos, como ocorreu neste estudo para o tratamento correspondente ao nível de lisina de $0,80 \%$.

Os resultados de rendimento de carcaça, comprimento de carcaça e espessura de toucinho encontram-se na Tab. 3.

Tabela 3. Rendimento de carcaça, comprimento carcaça pelo método brasileiro (MB), comprimento carcaça pelo método americano (MA), espessura de toucinho na $10^{\mathrm{a}}$ costela $\left(\mathrm{ET} 10^{\mathrm{a}}\right) \mathrm{e}$ espessura de toucinho na última costela (ETUL) de acordo com o nível de lisina da dieta de suínos dos 96 aos $120 \mathrm{~kg}$ de peso

\begin{tabular}{|c|c|c|c|c|c|c|}
\hline \multirow{2}{*}{ Característica } & \multicolumn{5}{|c|}{ Nível de lisina da ração (\%) } & \multirow{2}{*}{$\begin{array}{l}\mathrm{CV} \\
(\%)\end{array}$} \\
\hline & 0,5 & 0,6 & 0,7 & 0,8 & 0,9 & \\
\hline Rendimento de carcaça (\%) & 77,39 & 76,85 & 77,74 & 78,23 & 77,19 & 2,44 \\
\hline Comprimento carcaça MB (cm) & 103,05 & 101,40 & 102,65 & 100,50 & 103,60 & 2,91 \\
\hline Comprimento carcaça MA (cm) & 86,85 & 85,62 & 87,00 & 85,00 & 86,40 & 3,28 \\
\hline $\operatorname{ET} 10^{\mathrm{a}}(\mathrm{mm})^{1}$ & 14,75 & 15,33 & 17,00 & 21,17 & 20,75 & 22,54 \\
\hline $\operatorname{ETUL}(\mathrm{mm})^{2}$ & 14,50 & 14,80 & 15,60 & 18,20 & 15,90 & 18,19 \\
\hline
\end{tabular}

${ }^{1}$ Efeito linear $(\mathrm{P}<0,01): \hat{\mathrm{Y}}=5,31666+17,8333 \mathrm{X} ; \mathrm{R}^{2}=0,88$

${ }^{2}$ Efeito linear $(\mathrm{P}<0,04): \hat{\mathrm{Y}}=11,4600+6,20000 \mathrm{X} ; \mathrm{R}^{2}=0,45$.

Não foi observado efeito $(\mathrm{P}>0,10)$ do nível de lisina sobre o RC, CCMB ou CCMA. Estes resultados foram semelhantes aos relatados por Oliveira et al. (2002b), Kill et al. (2002a) e Kill et al. (2002b), que não observaram efeitos dos tratamentos sobre essas variáveis. Cline et al. (2000) observaram diminuição linear do RC, enquanto que Gonçalves et al. (1999) relataram aumento do $\mathrm{RC}$ e diminuição do CCMB e CCMA. Vários autores relataram valores de RC superiores (Souza Filho et al, 2000; Oliveira et al, 2002b; Kill et al., 2002a; Kill et al., 2002b). Eles obtiveram 82,1; 84,0; 83,1 e 84,6\%, respectivamente. Essas diferenças podem estar associadas ao grupo genético, ao sexo dos animais ou ao período de jejum imposto aos animais antes do abate. Neste experimento, ele foi inferior ao mencionado em outros trabalhos, e pode ter subestimado os valores de RC.

Foi observado efeito linear dos tratamentos sobre a ET10 ${ }^{\mathrm{a}}(\mathrm{P}<0,01)$ e ETUL $(\mathrm{P}<0,04)$, que aumentaram com o aumento do nível de lisina da ração. Friesen et al. (1995) e Cline et al. (2000) observaram aumento quadrático e diminuição linear da ET, respectivamente. O valor médio da $\operatorname{ET}_{10}{ }^{\mathrm{a}}(17,80 \mathrm{~mm})$ foi inferior ao obtido por Friesen et al. (1995) e Cline et al. (2000) que encontraram valores de 26,67 e $26,86 \mathrm{~mm}$, respectivamente.

Para a ETUL o valor médio $(15,80 \mathrm{~mm})$ foi inferior ao relatado por Souza Filho et al. (2000) e Oliveira et al. (2002b) que obtiveram $18,46 \mathrm{~mm}$ e $16,79 \mathrm{~mm}$ de ET e superior ao obtido por Kill et al. (2002a) e Kill et al. (2002b), respectivamente, 11,15 e $13,65 \mathrm{~mm}$. Segundo Souza Filho et al. (2000), maiores valores para espessura de toucinho possivelmente poderiam estar associados à presença de genes das raças Landrace e Duroc na composição do genótipo dos animais. Os diversos valores de ET obtidos de vários autores podem estar relacionados ao sexo dos animais. As fêmeas têm carcaças mais magras que os machos castrados na mesma idade.

De acordo com Friesen et al. (1994b), quando o 
suíno atinge a maturidade, o aumento na ingestão de alimentos pode resultar em aumento da deposição de lipídeos. Além disso, machos castrados na fase de terminação tardia melhoram seu desempenho de crescimento, via aumento da deposição de lipídeos na carcaça, em relação às fêmeas.

Os resultados de PPO, RP, PCAR, RCAR, PPAL E PBAR encontram-se na Tab. 4. Não foi observado efeito $(\mathrm{P}>0,10)$ dos tratamentos sobre o RP. Em diversos trabalhos (Kill et al., 2002a; Kill et al., 2002b; Oliveira et al., 2002b) não foi observado efeito do nível de lisina sobre o RP dos animais. O valor médio de RP (24,7\%) foi inferior ao encontrado por Oliveira et al. (2002b), 29,2\%, para machos castrados de grupo genético semelhante, e por Souza Filho et al. (2000) (27,0\%). Nos trabalhos de Kill et al. (2002a) e Kill et al. (2002b), os valores relatados foram de 32,2 e $32,8 \%$ de RP médio, respectivamente. Não foi evidenciado efeito $(\mathrm{P}>0,10)$ dos tratamentos sobre o PPO (com e sem osso), PCAR, RCAR, PPAL e PBAR, semelhante ao trabalho de Unruh et al. (1996), que observaram efeito do nível de lisina somente sobre o PPAL desossada.

Tabela 4. Peso do pernil com osso, peso do pernil sem osso, rendimento de pernil, peso do carré, rendimento de carré, peso da paleta e peso da barriga de acordo com o nível de lisina da dieta de suínos dos 96 aos $120 \mathrm{~kg}$ de peso

\begin{tabular}{lcccccc}
\hline \multirow{2}{*}{ Característica } & \multicolumn{5}{c}{ Nível de lisina da ração (\%) } & \multicolumn{1}{c}{ CV } \\
\cline { 2 - 7 } & 0,5 & 0,6 & 0,7 & 0,8 & 0,9 & $(\%)$ \\
\hline Pernil com osso (kg) & 22,582 & 22,958 & 21,590 & 22,710 & 21,818 & 4,12 \\
Pernil sem osso (kg) & 19,340 & 19,788 & 18,788 & 19,758 & 18,816 & 5,16 \\
Rendimento de pernil (\%) & 24,85 & 25,64 & 24,23 & 24,71 & 24,11 & 3,37 \\
Carré com filezinho (kg) & 11,404 & 11,056 & 11,226 & 11,328 & 11,656 & 4,32 \\
Rendimento de carré (\%) & 12,55 & 12,35 & 12,61 & 12,32 & 12,88 & 5,44 \\
Paleta com osso (kg) & 14,238 & 14,212 & 13,564 & 13,550 & 13,636 & 6,05 \\
Barriga sem costela (kg) & 12,400 & 11,532 & 11,598 & 12,300 & 12,022 & 9,84 \\
\hline
\end{tabular}

\section{CONCLUSÕES}

Conclui-se que suínos machos castrados selecionados para alta eficiência de crescimento, de 96 a $120 \mathrm{~kg}$, exigem $0,61 \%$ de lisina total $(0,190 \% /$ Mcal de EM), o que corresponde ao consumo estimado de $22,74 \mathrm{~g} /$ dia de lisina.

\section{REFERÊNCIAS BIBLIOGRÁFICAS}

AROUCA, C.L.C.; FONTES, D.O.; FERREIRA, W.M. et al. Exigências de lisina, com base no conceito de proteína ideal, para suínos machos castrados, de 95 a $122 \mathrm{~kg}$, selecionados para deposição de carne magra. Arq. Bras. Med. Vet. Zootec., v.56, p.773-781, 2004.

ASSOCIAÇÃO Brasileira de Criadores de Suínos. Método Brasileiro de Classificação de Carcaças. 1.ed. Estrela, RS: ABCS, 1973. 17p. (Publicação Técnica $\mathrm{N}^{\circ}$ 2).

BERTOL, T.M.; LUDKE, J.V.; FRAIHA, M. et al. Determinação das exigências de lisina digestível para suínos machos castrados e fêmeas dos 80 aos $120 \mathrm{~kg}$ de peso vivo. In: REUNIÃO ANUAL DA SOCIEDADE BRASILEIRA DE ZOOTECNIA, 37., 2000, Viçosa. Anais...Viçosa: SBZ, 2000. P.269 (CD-ROM).

CLINE, T.R.; CROMWELL, G.L.; CRENSHAW, T.D. et al. Further assessment of the dietary lysine requirement of finishing gilts. J. Anim. Sci., v.78, p.987-992, 2000.

CLOSE, W.H. Feeding new genotypes: establishing amino acid/energy requirements. In: COLE, D.J.A.; WISEMAN, J.; VARLEY, M.A. (Eds.). Principles of pig science. Loughborough: Nottingham University Press, 1994. P.123-140.

FRIESEN, K.G.; NELSSEN, J.L.; GOODBAND, R.D. et al. Influence of dietary lysine on growth and carcass composition of high-lean-growth gilts fed from 34 to 72 kilograms. J. Anim. Sci., v.72, p.1761-1770, 1994a.

FRIESEN, K.G.; NELSSEN, J.L.; GOODBAND, R.D. et al. The effect of dietary lysine on growth, carcass composition, and lipid metabolism in highlean growth gilts fed from 72 to 136 kilograms. $J$. 
Anim. Sci., v.73, p.3392-3401, 1995.

FRIESEN, K.G.; NELSSEN, J.L.; UNRUH, R.D. et al. Effects of the interrelationship between genotype, sex, and dietary lysine on growth performance and carcass composition in finishing pigs fed to either 104 or 127 kilograms. J. Anim. Sci., v.72, p.946-954, 1994b.

GASPAROTTO, L.F.; MOREIRA, I.; FURLAN, A.C. et al. Exigência de lisina, com base no conceito de proteína ideal, para suínos machos castrados de dois grupos genéticos, na fase de crescimento. Rev. Bras. Zootec., v.30, p.1742-1749, 2001.

GONÇALVES, T.M.; BERTECHINI, A.G.; DE KONING, G. et al. Lisina, energia, sexo e períodos experimentais em características de carcaça de suínos híbridos. In: CONGRESSO BRASILEIRO DE VETERINÁRIOS ESPECIALISTAS EM SUÍNOS, 9., 1999, Belo Horizonte. Anais... Belo Horizonte: ABRAVES, 1999. P.453-455.

HAHN, J.D.; BIEHL, R.R.; BAKER, D.H. Ideal digestible lysine level for early- and late-finishing swine. J. Anim. Sci., v.73, p.773-784, 1995.

KESSLER, A.M. Exigências nutricionais para máximo rendimento de carne em suínos. In: SIMPÓSIO SOBRE RENDIMENTO E QUALIDADE DA CARNE SUÍNA, 1998, Concórdia. Anais... Concórdia: EMBRAPACNPSA, 1998. p.18-25.

KILL, J.L.; DONZELE, J.L.; FERREIRA, A.S. et al. Efeito de planos de nutrição sobre as características de carcaça e rendimento de carne de leitoas com elevado potencial genético, abatidas aos 105kg. In: REUNIÃO ANUAL DA SOCIEDADE BRASILEIRA DE ZOOTECNIA, 39., 2002, Recife. Anais... Recife: SBZ, 2002a. (CD-ROM).

KILL, J.L.; DONZELE, J.L.; SILVA, M.V.G.B. et al. Efeito de planos de nutrição sobre as características de carcaça de leitoas com elevado potencial genético, abatidas aos $115 \mathrm{~kg}$. In: REUNIÃO ANUAL DA SOCIEDADE BRASILEIRA DE ZOOTECNIA, 39., 2002, Recife. Anais... Recife: SBZ, 2002b. (CD-ROM).

LOUGHMILLER, J.A.; NELSSEN, J.L.; GOODBAND, R.D. et al. Influence of dietary lysine on growth performance and carcass characteristics of late-finishing gilts. J. Anim. Sci., v.76, p.1075-1080, 1998.

MOREIRA, I.; GASPAROTTO, L.F.; FURLAN, A.C. et al. Exigência de lisina para machos castrados de dois grupos genéticos de suínos na fase de terminação, com base no conceito de proteína ideal. Rev. Bras. Zootec., v.31, p.96-103, 2002.

NUTRIENT requirements of swine. 10.ed. Washington: NRC, 1998. 189p.

OLIVEIRA, A. L.S.; DONZELE, J.L.; OLIVEIRA, R.F.M. et al. Lisina para suínos machos castrados de alto potencial genético para deposição de carne magra dos 110 aos $125 \mathrm{~kg}$. I Efeito sobre o desempenho. In: REUNIÃO ANUAL DA SOCIEDADE BRASILEIRA DE ZOOTECNIA, 39., 2002, Recife. Anais... Recife: SBZ, 2002a. (CD-ROM).

OLIVEIRA, A.L.S.; DONZELE, J.L.; OLIVEIRA, R.F.M. et al. Lisina para suínos machos castrados de alto potencial genético para deposição de carne magra dos 110 aos $125 \mathrm{~kg}$. II - Efeito sobre as características de carcaça. In: REUNIÃO ANUAL DA SOCIEDADE BRASILEIRA DE ZOOTECNIA, 39., 2002, Recife. Anais... Recife: SBZ, 2002b. (CD-ROM).

OLIVEIRA, A.L.S.; DONZELE, J.L.; OLIVEIRA, R.F.M. et al. Níveis de lisina para suínos machos castrados de alto potencial genético para deposição de carne magra dos 95 aos $110 \mathrm{~kg}$. In: REUNIÃO ANUAL DA SOCIEDADE BRASILEIRA DE ZOOTECNIA, 38., 2001, Piracicaba. Anais... Piracicaba: SBZ, 2001. P.817-819. (CD-ROM código 0727).

SISTEMA de análises estatísticas e genéticas SAEG. Viçosa: UFV, 2000. (Versão 8.0)

SOUZA FILHO, G.A.; LIMA, J.A.F.; FIALHO, E.T. et al. Efeito de planos de nutrição e de genótipos sobre características físicas de carcaça de suínos. Ciênc. Agrotec., v.24, p.1060-1067, 2000.

STAHLY, T.S.; CROMWELL, G.L.; TERHUNE, D. Responses of high, medium and low lean growth genotypes to dietary amino acid regimen. J. Anim. Sci., v.69, supplement 1, p.364, 1991. (Abstr.).

UNRUH, J.A.; FRIESEN, K.G.; STUEWE, S.R. et al. The influence of genotype, sex, and dietary lysine on pork subprimal cut yields and carcass quality of pigs fed to either 104 or 127 kilograms. $J$. Anim. Sci., v.74, p.1274-1283, 1996. 